\title{
Screening Fecal Methanogens in Five Orders of Mammals
}

\author{
Brett Higgins and Ann C. Wilkie \\ University of Florida
}

Faculty mentor: Ann Wilkie, Department of Soil and Water Sciences

\begin{abstract}
Animal waste has been studied as a potential fuel source via anaerobic digestion. Feces have also been used to inoculate biodigesters. Biodigesters are a waste treatment solution that use anaerobic digestion to convert organic matter into methane. They utilize microbes to break down organic matter into substrates which are then converted into methane as fuel. The final step's productivity depends on the methanogen content of the biodigester. This study evaluated the feces of captive animals for use as a methanogenic inoculum. The aim was to assess the potential of different feces for methanogen contribution through a literature review and sample analysis via fluorescence microscopy to observe F420 autofluorescence. Coenzyme F420 is a fluorescent coenzyme involved in redox reactions in methanogens and is used in their identification and observation. The samples were from herbivores in the orders Rodentia (rodents), Lagomorpha (rabbits), Perissodactyla (odd-toed ungulates), Artiodactyla (even-toed ungulates), and Diprotodontia (some marsupials). The literature review favored goats and sheep over the other animals in the study. The feces from each animal species tested were observed to have some methanogen presence, but the levels were low and differences were not discernible. Overall, the results of the sample analyses were inconclusive due to the scarcity of methanogens and obscuration due to foliage fragments.

Keywords: Fecal, Methanogens, Coenzyme F420, Anaerobic digestion, Biodigester, Inoculum
\end{abstract}

\section{Introduction}

Biodigesters are a waste treatment solution used in a variety of countries and that show promise worldwide. Their benefits extend to both developed and less-developed countries as not only a waste solution but also as a renewable fuel source (Cornejo \& Wilkie, 2010; Wilkie, 2008). Other environmental benefits include odor reduction, pathogen control, conservation of nutrients, and reduction in greenhouse gas emissions (Wilkie, 2005).

Biodigesters are reactor vessels that use anaerobic digestion for the engineered methanogenic decomposition of organic matter. Anaerobic digestion is a biological process by which a complex mixture of symbiotic microorganisms transforms organic materials under oxygen-free conditions into biogas, a mixture of mostly methane and carbon dioxide. The process consists of a series of reactions through which organic matter is converted in a stepwise fashion to methane and carbon dioxide (Figure 1). Polymers are hydrolyzed to oligomers or monomers, which are then metabolized by fermentative bacteria with the production of hydrogen $\left(\mathrm{H}_{2}\right)$, carbon dioxide 
$\left(\mathrm{CO}_{2}\right)$, and volatile organic acids such as acetate, propionate, and butyrate. The volatile organic acids other than acetate are converted to methanogenic precursors $\left(\mathrm{H}_{2}, \mathrm{CO}_{2}\right.$, and acetate) by the syntrophic acetogens. Finally, the methanogenic bacteria produce methane from acetate or from $\mathrm{H}_{2}$ and $\mathrm{CO}_{2}$ (Wilkie, 2005).

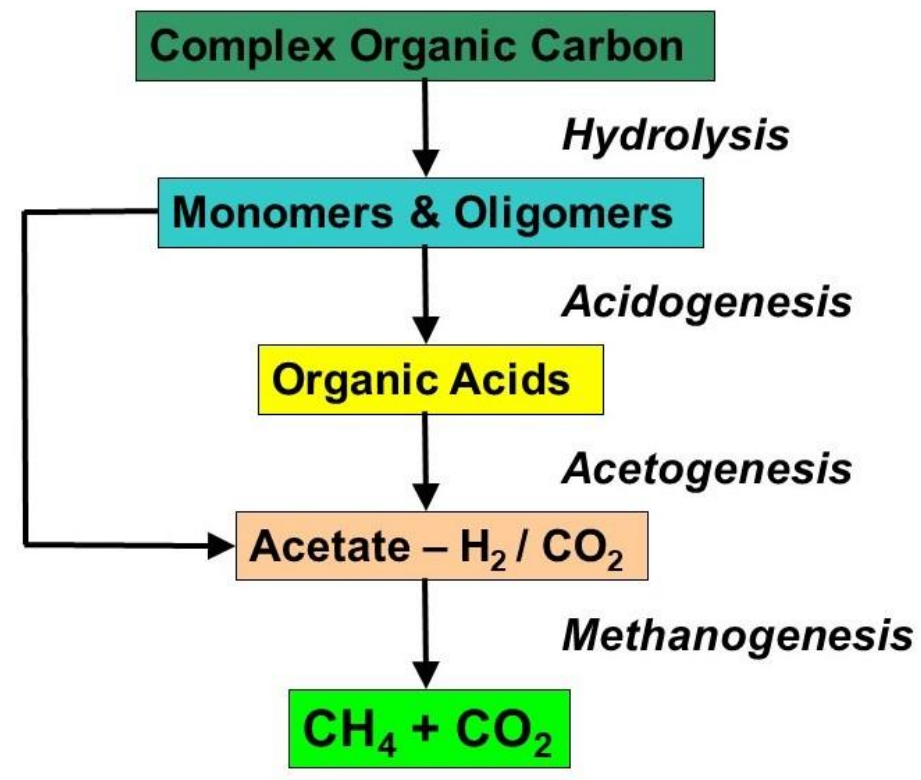

Figure 1. Multiphase nature of anaerobic digestion (Wilkie, 2005)

Anaerobic digestion occurs naturally in oxygen-free environments such as landfills, sediments, saturated soils, and animal intestinal tracts (Wilkie et al., 1986). Thus, animal manure will contain anaerobic microbes to a varying degree, depending on the animal species. Methanogen concentration in the vertebrate gut microflora of a variety of mammalian species is around $0.5 \%$ to $3 \%$ of the overall microflora (Lamendella et al., 2011; Sorlini et al., 1988; St-Pierre \& Wright, 2012a, 2012b).

Methanogen concentration is one of the limiting factors in the start up of an anaerobic digester. Often an anaerobic digester is inoculated with feces with the intent of adding anaerobes and bacteria such as Firmicutes and Bacteroides to breakdown and digest waste and process it much like they would in a gut microbiome (Sun et al., 2015). The quality and quantity of inoculum are critical to the performance, time required, and stability of biomethanogenesis during start-up (Wilkie, 2008). 
With methanogenesis being a pivotal step, an inoculum with high methanogen content is desirable to use as a biological starter for a new digester. For that purpose, this study first reviewed the available literature to identify feces that would be most suitable for the inoculation of anaerobic digesters.

Coenzyme F420 is a low molecular weight methanogenic coenzyme which fluoresces with a strong absorption at $420 \mathrm{~nm}$ (Figure 2). It occurs at varying levels in all methanogenic species. The fluorescent property of coenzyme F420 has been used as a tentative means of identifying methanogenic colonies in roll-tubes (Edwards \& McBride, 1975) and individual morphotypes in mixed cultures by fluorescence microscopy (Doddema \& Vogels, 1978; Mink \& Dugan, 1977). The fluorescence has also been used to monitor the growth rates of methanogens in pure culture (Taya et al., 1986).<smiles>CC(OP(=O)([O-])OC[C@H](O)[C@H](O)[C@H](O)Cn1c2nc(=O)[nH]c(=O)c-2cc2ccc(O)cc21)C(=O)NC(CCC(=O)NC(CCC(=O)[O-])C(=O)[O-])C(=O)[O-]</smiles>

Figure 2. Coenzyme F420

As such, the experimental part of this study involved autofluorescence screening of various animal waste samples for methanogen content to use as potential biodigester methanogenic inocula.

\section{Materials and Methods}

This study consisted initially of a literature review focused on previous studies that have reported the methanogen content of different animal wastes. The methods included analysis of relevant figures and data in order to identify similarities between animals in the study and those obtainable in the local area. 
Following the literature review, samples were collected from the local area. These samples were fecal pellets from five mammalian orders including, Perissodactyla (donkey), Artiodactyla (sheep, goat, llama), Rodentia (Patagonian cavy, hamster, grey squirrel), Lagomorpha (rabbit), and Diprotodontia (wallaby). The fecal samples were obtained fresh from Petting Zoo Ocala, except for the squirrel droppings which were acquired at the University of Florida. Samples from the Petting Zoo Ocala underwent a transit time of approximately 2 hours. Coenzyme F420 autofluorescence was used to scan the feces for the presence of methanogens. A Nikon LABOPHOT microscope equipped for epifluorescence was used for observation of wet mounts and dilutions. Photomicrographs were taken using a SPOT Insight 2MP CCD Scientific Color Digital Camera System.

The fecal samples were processed in a variety of ways. First, a simple wet mount was prepared in which the feces were softened with water and smeared upon the slide. This showed some visible methanogens. However, due to the presence of large obstructing foliage fragments from the feces, the methanogens were hard to observe, as seen in Figure 3. Due to this, the samples were then diluted in $1.5 \mathrm{ml}$ micro-centrifuge tubes.

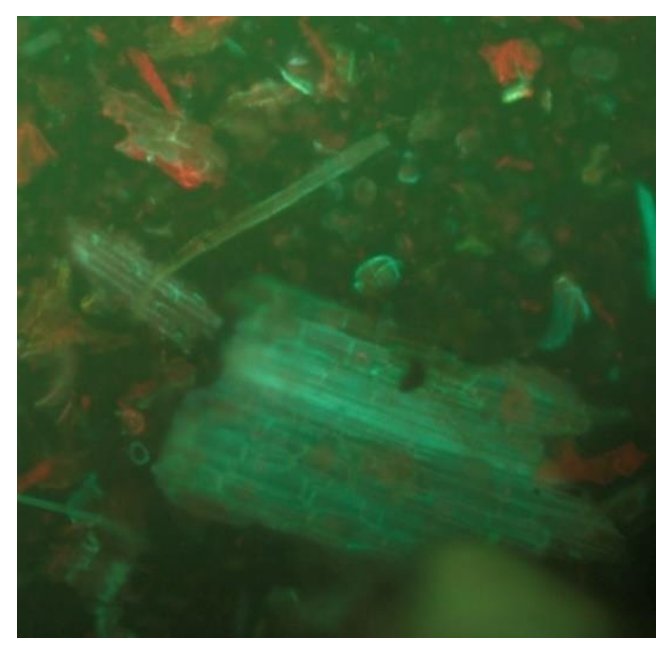

Figure 3. Photomicrograph of undiluted goat feces illustrating high foliage presence at 100x magnification

The first dilution trial in the micro-centrifuge tubes was conducted at $1.25 \mathrm{ml}$ of feces to 0.25 $\mathrm{ml}$ of water (5:1). This dilution, while yielding some spots with the fluorescence described in Doddema \&Vogel's paper, was ineffective due to the fact that these spots appeared under, or as 
part of, the foliage of the feces. Therefore, it was decided to further dilute the samples in an effort to reduce fecal foliage obstruction.

The subsequent dilutions included samples of $0.1 \mathrm{ml}$ feces to $1.4 \mathrm{ml}$ biodigester liquid (1:14), $0.5 \mathrm{ml}$ feces to $1 \mathrm{ml}$ biodigester liquid (1:2), and $1 \mathrm{ml}$ feces to $0.5 \mathrm{ml}$ biodigester liquid (2:1). The biodigester liquid was obtained from a $4 \mathrm{~L}$ mesophilic anaerobic digester fed with food waste (Wilkie et al., 2004). The use of liquid from a biodigester was chosen for these dilutions in order to enrich the samples with methanogens and avoid the compounding of methanogen scarcity (Figure 4). As such, the $0.1 \mathrm{ml}$ to $1.4 \mathrm{ml}$ dilution showed the best results for removal of fecal foliage. Following that, the process was repeated with water in place of liquid from the biodigester to avoid false positives of methanogens in the samples due to methanogen presence from the biodigester liquid.

All of the above dilutions were viewed after homogenizing on a pulsing vortex mixer (Fisher Scientific) for one minute. Additional repetitions were performed via micro-centrifugation of the homogenized dilutions at 5,000 rpm for 30 seconds in an Eppendorf Minispin Plus ${ }^{\mathrm{TM}}$ (Eppendorf AG, Hamburg, Germany), but subsamples of the pellet proved to be too occluded while samples of the supernatant showed no autofluorescence.

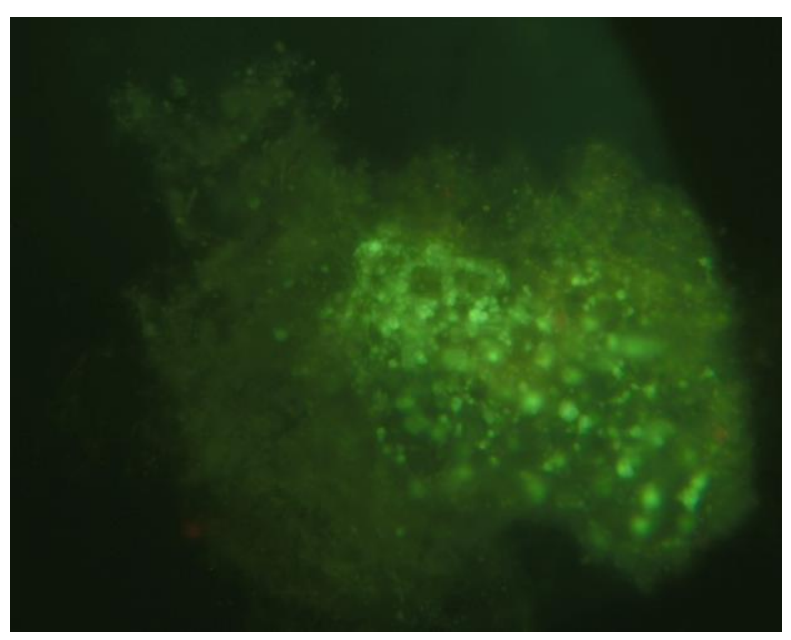

Figure 4. Photomicrograph of methanogens in food waste biodigester liquor at 400x magnification 


\section{Results}

The data acquired from the literature review appeared to favor goats and sheep over the other animals in the study. They had vastly higher methane outputs in the tests reported in Hackstein \& van Alen (1996, Table 1). This would also be expected given their identity as ruminants, which are known to produce large amounts of methane. As seen in Table 1, sheep and goats were shown to have higher methane production than the other animals used in our study. Squirrels were the only mammals in our study not categorized as a methanogenic species (Table 1).

Table 1. Methane release by feces of animals in this study (subset from Hackstein \& van Alen, 1996)

\begin{tabular}{llccc}
\hline \multicolumn{1}{c}{ Animal } & \multicolumn{1}{c}{$\begin{array}{c}\text { Relative Animal in } \\
\text { Hackenstein study }\end{array}$} & $\begin{array}{c}\text { Methane Average } \\
\mathrm{nmol} / \mathrm{g} / \mathrm{h}\end{array}$ & $\begin{array}{c}\text { Methane Max } \\
\mathrm{nmol} / \mathrm{g} / \mathrm{h}\end{array}$ & $\mathrm{M} / \mathrm{N}^{*}$ \\
\hline Sheep & Capra hircus & 4230 & 10000 & $\mathrm{M}$ \\
Goat & Capra hircus & 4230 & 10000 & $\mathrm{M}$ \\
Domestic Donkey & Equus przewalskii caballus & 118 & 286 & $\mathrm{M}$ \\
Wallaby & Wallabia rufogrisea & 185 & 283 & $\mathrm{M}$ \\
Rabbit & Oryctolagus cunniculus & 42 & 227 & $\mathrm{M}$ \\
Llama & Lama g. guanicoe & 73 & 202 & $\mathrm{M}$ \\
Patagonian Cavy & Dolichotis patagonum & 25 & 145 & $\mathrm{M}$ \\
Hamster & Mesocricetus auratus & 9 & 29 & $\mathrm{M}$ \\
Grey Squirrel & Sciurus carolinensis & 0.01 & 4 & $\mathrm{~N}$ \\
\hline
\end{tabular}

* M/N denotes whether the animal feces is classified as methanogenic $(\mathrm{M})$ or as a non-producer of methane $(\mathrm{N})$.

In terms of the methanogen presence identified in the photomicrographs, the results were relatively inconclusive. The feces from all species tested were observed to have at least some methanogens present. However, the levels were low and the variation between them was not quantifiable due to foliage interference. Additionally, as referenced in the methods, the foliage initially obscured large portions of the viewing area and may have inhibited observation of the methanogens. Conversely, with the dilutions, a corresponding drop in methanogen presence occurred causing them to be rare to find within the dilutions. Even the goats, which were favored in the literature, showed few to no methanogens in the diluted samples observed.

Within this study, squirrel feces, as seen in Figure 5, were an anomaly. In looking at the squirrel pellets directly, methanogens were not only readily evident, but also had little to no obstruction from foliage. Visibly, the squirrel feces showed a greater density of fecal 
methanogens than any of the other samples, including liquid from the digester. The squirrel feces displayed methanogens with no manipulation of the sample necessary.

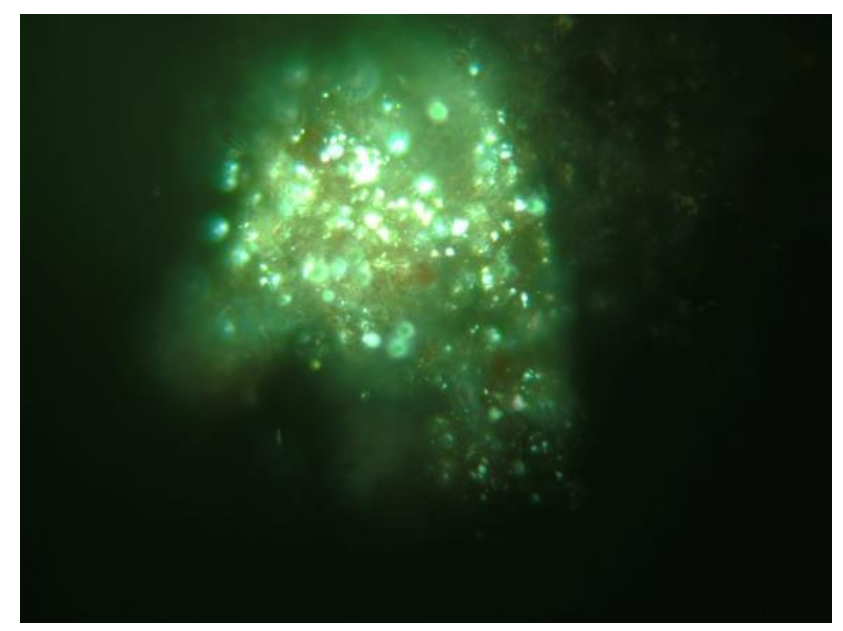

Figure 5. Photomicrograph of methanogens in undiluted squirrel feces at $400 x$ magnification

\section{Discussion}

Despite the microscopy results showing a greater density of methanogens in the squirrel feces than the others, the meaning of the results is unclear, due to potential confounding. This lack of clarity is exacerbated by the low amounts of methanogen levels in animals with high expected methanogen content. Other studies have shown that goat and sheep manures are viable substrates for methane production (Sanchez \& Wilkie, 2018). Due to this discrepancy, it is likely that these results are confounded instead by some other variable, such as freshness of the samples, handling time, or oxygen exposure. These factors are a result of temporal and spatial constraints on access to the animals and their feces, e.g. transport time was required for the feces from most of the animals as they were located further away than the squirrels.

Additionally, in the event that the results from the photomicrographs are indicative of reality, it is a result that is sub-optimal when looking at potential inocula for a biodigester. This is mostly due to the difficulty in obtaining squirrel feces and the small size of squirrel feces in comparison to the other organisms. With this in mind, and noting the discrepancies between the photomicrographs, it is probable that the feces of larger ruminants from the group Artiodactyla are preferable rather than Rodentia for biodigester inoculation purposes. 


\section{Conclusions}

Methanogenic bacteria were found in all samples screened. It was expected that ruminants would provide feces with greater methanogen density than other animal sources. The literature review did favor sheep and goats. However, the results of the fecal sample screening were inconclusive due to the scarcity of methanogens and obscuration due to foliage. The methanogen presence observed in the fecal samples was very similar, except for squirrels. Squirrels were found to exhibit a greater methanogen density in their feces than anticipated from the literature. The high number of methanogenic bacteria found in squirrel feces is a novel finding and warrants further study.

\section{Acknowledgements}

This research was conducted as part of the 2018-19 CALS University Scholars Program at the BioEnergy and Sustainable Technology Laboratory, Soil and Water Sciences Department, UF/IFAS.

\section{References}

Cornejo, C. and Wilkie, A.C. (2010). Greenhouse gas emissions and biogas potential from livestock in Ecuador. Energy for Sustainable Development, 14(4), 256-266. https://doi.org/10.1016/j.esd.2010.09.008

Doddema, H.J. and Vogels, G.D. (1978). Improved identification of methanogenic bacteria by fluorescence microscopy. Applied and Environmental Microbiology, 36(5), 752-754. https://www.ncbi.nlm.nih.gov/pmc/articles/PMC243133/

Edwards, T. and McBride, B.C. (1975). New method for the isolation and identification of methanogenic bacteria. Applied Microbiology, 29(4), 540-545. https://aem.asm.org/content/29/4/540

Hackstein, J.H.P. and van Alen, T.A. (1996). Fecal methanogens and vertebrate evolution. Evolution, 50(2), 559-572. https://doi.org/10.1111/j.1558-5646.1996.tb03868.x

Lamendella, R., Santo Domingo, J.W., Ghosh, S., Martinson, J. and Oerther, D.B. (2011). Comparative fecal metagenomics unveils unique functional capacity of the swine gut. BMC Microbiology, 11(1), 103. https://doi.org/10.1186/1471-2180-11-103

Mink, R.W. and Dugan, P.R. (1977). Tentative identification of methanogenic bacteria by fluorescence microscopy. Applied and Environmental Microbiology, 33(3), 713-717. https://www.ncbi.nlm.nih.gov/pmc/articles/PMC170748/

Sanchez, C. and Wilkie, A.C. (2017). Bioenergy production potential from small ruminant manure. Journal of Undergraduate Research, 18(3), Summer 2017, p.1-4. http://ufdc.ufl.edu/UF00091523/00828

Sorlini, C., Brusa, T., Ranalli, G. and Ferrari, A. (1988). Quantitative determination of methanogenic bacteria in the feces of different mammals. Current Microbiology, 17(1), 33-36.

https://doi.org/10.1007/bf01568816 
St-Pierre, B. and Wright, A.-D.G. (2012a). Diversity of gut methanogens in herbivorous animals. Animal, 7(s1), 49-56. https://doi.org/10.1017/s1751731112000912

St-Pierre, B. and Wright, A.-D.G. (2012b). Molecular analysis of methanogenic archaea in the forestomach of the alpaca (Vicugna pacos). BMC Microbiology, 12(1), 1. https://doi.org/10.1186/1471-2180-12-1

Sun, L., Pope, P.B., Eijsink, V.G.H. and Schnürer, A. (2015). Characterization of microbial community structure during continuous anaerobic digestion of straw and cow manure. Microbial Biotechnology, 8(5), 815-827. https://doi.org/10.1111/1751-7915.12298

Taya, M., Aoki, N. and Kobayashi, T. (1986). Kinetic evaluation and monitoring of methanogen culture based on fluorimetry. Applied Microbiology and Biotechnology, 23(5), 342-347. https://doi.org/10.1007/BF00257030

Wilkie, A.C. (2005). Anaerobic digestion: biology and benefits. In: Dairy Manure Management: Treatment, Handling, and Community Relations. NRAES-176, pp. 63-72. Ithaca, NY: Natural Resource, Agriculture, and Engineering Service, Cornell University. http://biogas.ifas.ufl.edu/Publs/NRAES176-p63-72-Mar2005.pdf

Wilkie, A.C. (2008). Biomethane from biomass, biowaste and biofuels. In Bioenergy, J.D. Wall, C.S. Harwood and A. Demain (Eds.), pp. 195-205. Washington D.C.:ASM Press. http://biogas.ifas.ufl.edu/Publs/Bioenergy CH16 ASM Press 2008.pdf

Wilkie, A., Goto, M., Bordeaux, F.M. and Smith, P.H. (1986). Enhancement of anaerobic methanogenesis from Napiergrass by addition of micronutrients. Biomass, 11(2), 135-146. https://doi.org/10.1016/0144-4565(86)90043-0

Wilkie, A.C., Smith, P.H. and Bordeaux, F.M. (2004). An economical bioreactor for evaluating biogas potential of particulate biomass. Bioresource Technology, 92(1), 103-109. https://doi.org/10.1016/j.biortech.2003.08.007 